ORIGINAL ARTICLE

\title{
Gene amplification and protein expression of EGFR and HER2 by chromogenic in situ hybridisation and immunohistochemistry in atypical adenomatous hyperplasia and adenocarcinoma of the lung
}

\author{
H Awaya, Y Takeshima, O Furonaka, N Kohno, K Inai
}

J Clin Pathol 2005;58:1076-1080. doi: 10.1136/icp.2004.025585

See end of article for
authors' affiliations
......................
Correspondence to:
Dr H Awaya, Department
of Pathology, Graduate
School of Biomedical
Sciences, Hiroshima
University, 1-2-3 Kasumi,
Minami-ku, Hiroshima
$734-8551$, Japan;
koinai@hiroshima-u.ac.jp
Accepted for publication
3 March 2005

\begin{abstract}
Aims: To investigate the importance of gene amplification and EGFR (epidermal growth factor receptor) and HER2 protein expression during the progression of adenocarcinoma of the lung.

Methods: EGFR and HER2 gene amplification was examined in atypical adenomatous hyperplasia (AAH), bronchioloalveolar carcinoma (BAC), and adenocarcinoma with mixed subtypes (MX) by chromogenic in situ hybridisation $(\mathrm{CISH})$, and protein expression was examined by immunohistochemistry using paraffin wax embedded tissues.

Results: EGFR and HER2 gene amplification was found in four and two of 86 cases, respectively, and was detected only in the invasive components of MX. EGFR and HER2 protein expression was seen in 24 and 18 of 86 cases, respectively. EGFR and HER2 proteins were not expressed in AAH but were expressed in one BAC case each. EGFR and HER2 proteins were expressed in 23 and 17 of 55 adenocarcinomas with $M X$. EGFR and HER2 protein expression was seen more often in the invasive components than in the BAC components of $M X$, and increased significantly as lesions progressed from $A A H$ to BAC, early $M X$, and overt MX. Because EGFR and HER2 protein expression was frequently seen without gene amplification, other mechanisms apart from gene amplification may be associated with protein expression.

Conclusions: EGFR and HER2 gene amplification may be a late event and EGFR and HER2 protein expression may be associated with the development of adenocarcinoma of the lung.
\end{abstract}

A denocarcinoma is the most frequent histological type of carcinoma of the lung. According to the World Health Organisation classification, ${ }^{1}$ atypical adenomatous hyperplasia (AAH) is a preneoplastic lesion of adenocarcinoma, and bronchioloalveolar carcinoma (BAC) is a noninvasive type of carcinoma. Adenocarcinoma with mixed subtypes (MX), which is the most common type of adenocarcinoma, usually includes BAC-type carcinoma in the periphery and invasive carcinoma in the central portion. Based on these morphological findings, it has been suggested that at least some adenocarcinomas occur as a result of progression from $\mathrm{AAH}$ through BAC to invasive adenocarcinoma..$^{2-4}$

"Chromogenic in situ hybridisation allows comparison with histological findings obtained by microscopy"

Epidermal growth factor receptor EGFR/erbB1 and HER2/ erbB2 are members of the EGFR family of type I receptor tyrosine kinases. ${ }^{5}$ Homodimerisation or heterodimerisation of these receptors appears to promote signal transduction pathways, including angiogenesis, inhibition of apoptosis, and cell growth. The EGFR gene is located on chromosome 7p12. The frequency of EGFR expression is high in non-small cell lung cancer (NSCLC). In previous studies, EGFR expression was detected in $38-75 \%$ of adenocarcinomas, $30-82 \%$ of squamous cell carcinomas, and $33 \%$ of large cell carcinomas. $^{6-8}$ In contrast, the frequency of EGFR gene amplification, as determined by fluorescent in situ hybridisation (FISH), has been reported to be $9 \%$ in NSCLC. ${ }^{6}$ HER2, which is located on chromosome $17 \mathrm{q} 21$, is considered a heterodimerisation partner for other members of the HER family. Among NSCLC, HER2 expression is seen frequently in adenocarcinoma and large cell carcinoma and is associated with poor prognosis. ${ }^{10}$ In addition, HER2 expression was reported in $29-35 \%$ of adenocarcinomas, $1-18 \%$ of squamous cell carcinomas, and $0-20 \%$ of large cell carcinomas. ${ }^{10-13}$ The frequency of HER2 gene amplification, as determined by FISH, was reported to be $2-4 \%$ in NSCLC. ${ }^{11-13}$

Chromogenic in situ hybridisation (CISH) was introduced in 2000 and has been used to examine several types of carcinoma, such as breast carcinoma, prostate carcinoma, and extramammary Paget's disease. ${ }^{14-18}$ However, there have been no previous reports of analysis of gene amplification in carcinoma of the lung using CISH. Although FISH is a standard technique for gene amplification, CISH has been reported to show a good correlation with gene amplification by FISH. Moreover, CISH allows comparison with histological findings obtained by microscopy.

In our present study, gene amplification and protein expression of EGFR and HER2 were examined by CISH in $\mathrm{AAH}, \mathrm{BAC}$, and MX, and the significance of the findings was analysed on the assumption of progression from $\mathrm{AAH}$ through BAC to invasive adenocarcinoma.

\section{MATERIALS AND METHODS}

Tissue samples

Table 1 shows the case profiles of the patients studied. Tissue samples were obtained from 86 patients, comprising 34 men

\footnotetext{
Abbreviations: AAH, atypical adenomatous hyperplasia; BAC, bronchioloalveolar carcinoma; CISH, chromogenic in situ hybridisation; EGFR, epidermal growth factor receptor; FISH, fluorescent in situ hybridisation; $M X$, adenocarcinoma with mixed subtypes; NSCLC, nonsmall cell lung cancer
} 
Table 1 Clinicopathological profiles of patients studied

\begin{tabular}{|c|c|c|c|c|}
\hline Feature & BAC $(n=31)$ & Early $M X(n=22)$ & Overt $M X(n=33)$ & p Value \\
\hline \multicolumn{5}{|l|}{ Sex } \\
\hline Male & 11 & 9 & 14 & \\
\hline Female & 20 & 13 & 19 & \\
\hline Mean (range) age (years) & $41-83(67)$ & $40-83(63)$ & $41-85(63)$ & \\
\hline Mean (range) tumour size $(\mathrm{cm})$ & $0.2-2.5(1.3)$ & $0.8-3.0(2.0)$ & $1.1-7.0(2.7)$ & $<0.0001$ \\
\hline Lymph node metastasis positive cases (\%) & 0 & $1 / 22(4.5 \%)$ & $9 / 30(30 \%)$ & 0.0008 \\
\hline
\end{tabular}

The Kruskal Wallis test was used to assess the $p$ values among $B A C$, early $M X$, and overt $M X$.

BAC, bronchioloalveolar carcinoma; MX, adenocarcinoma with mixed subtypes.

and 52 women aged 40-85 years (median, 64.6), who underwent surgery during the period between 1988 and 2001. Some of the patients with BAC or MX had one or more lesion defined as AAH. Therefore, we examined $14 \mathrm{AAH}$ lesions, 31 BAC lesions, and 55 MX lesions, defined according to the World Health Organisation classification. ${ }^{1}$ Among MX, cases showing $\mathrm{BAC}$ in $<50 \%$ and $>50 \%$ of the area of the lesion were defined as early $\mathrm{MX}$ and overt $\mathrm{MX}$, respectively.

\section{Chromogenic in situ hybridisation}

Sections ( $4 \mu \mathrm{m}$ thick) were cut from paraffin wax blocks and dewaxed. Antigen retrieval and enzyme digestion were performed using a formalin fixed, paraffin wax embedded tissue pretreatment kit (Zymed, San Francisco, California, USA). A digoxigenin labelled EGFR or HER2 DNA probe (Zymed) was applied, and the sections were covered with coverslips and denatured on a hot plate at $94^{\circ} \mathrm{C}$. Hybridisation was performed overnight at $37^{\circ} \mathrm{C}$. After removing the coverslips, HER2 signals were detected using a CISH detection kit (Zymed). A peroxidase quenching solution was applied to the sections, followed by non-specific blocking solution for 10 minutes at room temperature, fluorescein isothiocyanate-sheep antidigoxigenin for 30 minutes at room temperature, horseradish peroxidase-goat anti-fluorescein isothiocyanate for 30 minutes at room temperature, and $\mathrm{DAB}$ chromogen for 30 minutes at room temperature. Finally, the slides were counterstained with haematoxylin.

Signals were seen as dark brown dots. According to previous reports, ${ }^{14-18}$ a gene copy number of six or more in the nucleus in more than $50 \%$ of tumour cells was taken to indicate amplification of the EGFR and/or HER2 genes (fig 1). Cases with three to five gene copies were considered aneuploid. Immunohistochemistry and CISH were evaluated independently.

\section{Immunohistochemistry for EGFR and HER2}

Immunohistochemistry was performed as reported previously. ${ }^{4}$ Briefly, $2 \mu \mathrm{m}$ thick sections were cut from paraffin wax blocks containing representative areas of the tumours.
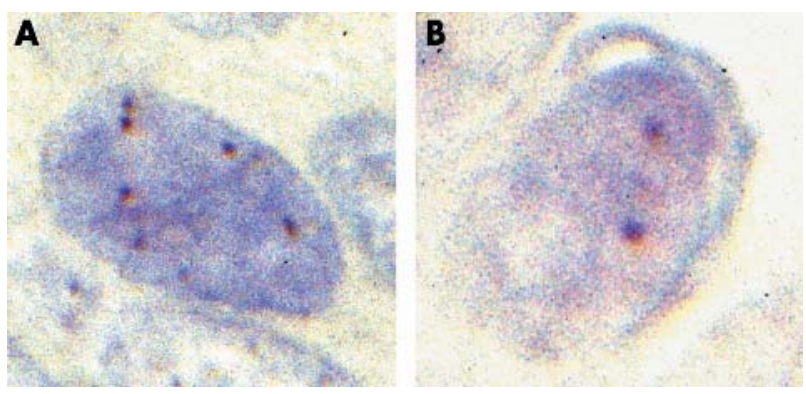

Figure 1 Evaluation of EGFR (epidermal growth factor receptor) gene amplification by chromogenic in situ hybridisation. (A) Six gene copies were seen. This case was considered positive for gene amplification. (B) Two gene copies were seen. This case was considered negative.
Antigen retrieval was performed by autoclaving. Anti-EGFR antibody (EGFR.113; Novocastra, Newcastle upon Tyne, UK) and anti-c-erbB-2 antibody (CB11; Novocastra) at dilutions of $1 / 50-1 / 100$ were used according to the streptavidin-biotinperoxidase method. As a negative control, the primary antibody was omitted, and a tumour specimen of invasive lobular carcinoma of the breast was used as a positive control.

\section{Evaluation of immunohistochemistry for EGFR and HER 2}

Immunohistochemistry for EGFR and HER2 was evaluated according to the Herceptest (Dako Cytomation, Carpinteria, California, USA) protocol. If more than $10 \%$ of the tumour cells showed EGFR or HER2 expression over the entire cell membrane, the case was considered positive. Diffuse and granular cytoplasmic expression and partial membranous expression were considered negative for both EGFR and HER2.

\section{Statistical analysis}

Differences in the expression of EGFR and HER2 between AAH, BAC, early MX, and overt MX were analysed by the Kruskal-Wallis test and one way analysis of variance. Differences were considered significant at $\mathrm{p}<0.05$.

\section{RESULTS}

EGFR and HER2 gene amplification in AAH and adenocarcinoma of the lung (table 2)

EGFR and HER2 gene amplification was seen in four and two of 86 cases, respectively. In all of these cases, gene amplification was detected only in the invasive components of MX. EGFR aneuploidy was seen in none of the 14 cases of $\mathrm{AAH}$, three of the 34 cases of BAC, and two of the 55 cases of MX. In MX, aneuploidy was seen only in the invasive components of overt MX.

\section{EGFR and HER2 protein expression in $A A H$ and adenocarcinoma of the lung}

Table 3 shows the protein expression results. EGFR and HER2 expression increased significantly as the lesions progressed from $\mathrm{AAH}$ to BAC, early $\mathrm{MX}$, and overt $\mathrm{MX}$, and was seen more frequently in invasive components than in BAC components of MX (fig 2). Partial membrane expression-hemilateral or basolateral staining-was seen in less than $10 \%$ of the tumour cells in AAH and BAC. EGFR gene amplification was seen in four cases, three of which also showed protein overexpression (table 4). HER2 gene amplification was seen in two cases, both of which showed protein overexpression.

\section{DISCUSSION}

In our present study, we examined EGFR and HER2 gene amplification by CISH. The frequencies of EGFR and HER2 gene amplification were similar to those reported previously. ${ }^{61-13}$ Therefore, CISH appears to be useful for the 
Table 2 EGFR and HER2 gene amplification in AAH and adenocarcinoma of the lung

\begin{tabular}{|c|c|c|c|c|c|}
\hline \multirow[b]{2}{*}{ Gene } & \multicolumn{4}{|c|}{ Adenocarcinoma } & \multirow[t]{2}{*}{ Total $(n=86)$} \\
\hline & AAH $(n=14)$ & BAC $(n=31)$ & Early $M X(n=22)$ & Overt $M X(n=33)$ & \\
\hline EGFR & 0 & 0 & 2 & 2 & $4(4.7 \%)$ \\
\hline HER2 & 0 & 0 & 1 & 1 & $2(2.3 \%)$ \\
\hline
\end{tabular}

AAH, atypical adenomatous hyperplasia; BAC, bronchioloalveolar carcinoma; EGFR, epidermal growth factor receptor; MX, adenocarcinoma with mixed subtypes.

detection of gene amplification in adenocarcinoma of the lung. Because gene amplification was seen only in invasive components of MX, gene amplification may be a late event in the development of adenocarcinoma of the lung. However, EGFR aneuploidy may not play an important role in the progression of adenocarcinoma of the lung, because aneuploidy was not associated with histological change.

In our present study, EGFR and HER2 protein expression increased in parallel with histological change. These results suggest that EGFR and HER2 expression may be associated with development of adenocarcinoma of the lung. Synchronous expression of both EGFR and HER2 may indicate heterodimerisation. Synchronous expression was seen in ten of the lesions, similar to previous reports, ${ }^{19}$ and increased significantly as histological changes became greater. These results suggest that synchronous expression may also be associated with the development of adenocarci- noma of the lung. The frequencies of EGFR and HER2 expression in our present study were somewhat lower than those reported previously. ${ }^{6-8}{ }^{11-13}$ This might be the result of case selection bias-a large number of BAC cases were included in our present study. In addition, differences in the criteria used for the evaluation of protein expression and in antibodies used may have influenced the results. Saad et al reported HER2 expression in 19 of $50 \mathrm{MX}$ samples and three of 50 BAC samples using the Herceptest (Dako Cytomation). ${ }^{20}$ The anti-c-erbB2 antibody clone CB11 used in our study has been reported to show less false positives than the Herceptest. ${ }^{21}$ However, various frequencies of EGFR expression have been reported previously. Hirsch et al reported EGFR expression in 28 of 69 MX cases and eight of 10 BAC cases using a semiquantitative method for evaluation and anti-EGFR antibody (catalogue number 28-0005; Zymed Laboratories). ${ }^{6}$ Mukohara et al also used an anti-EGFR
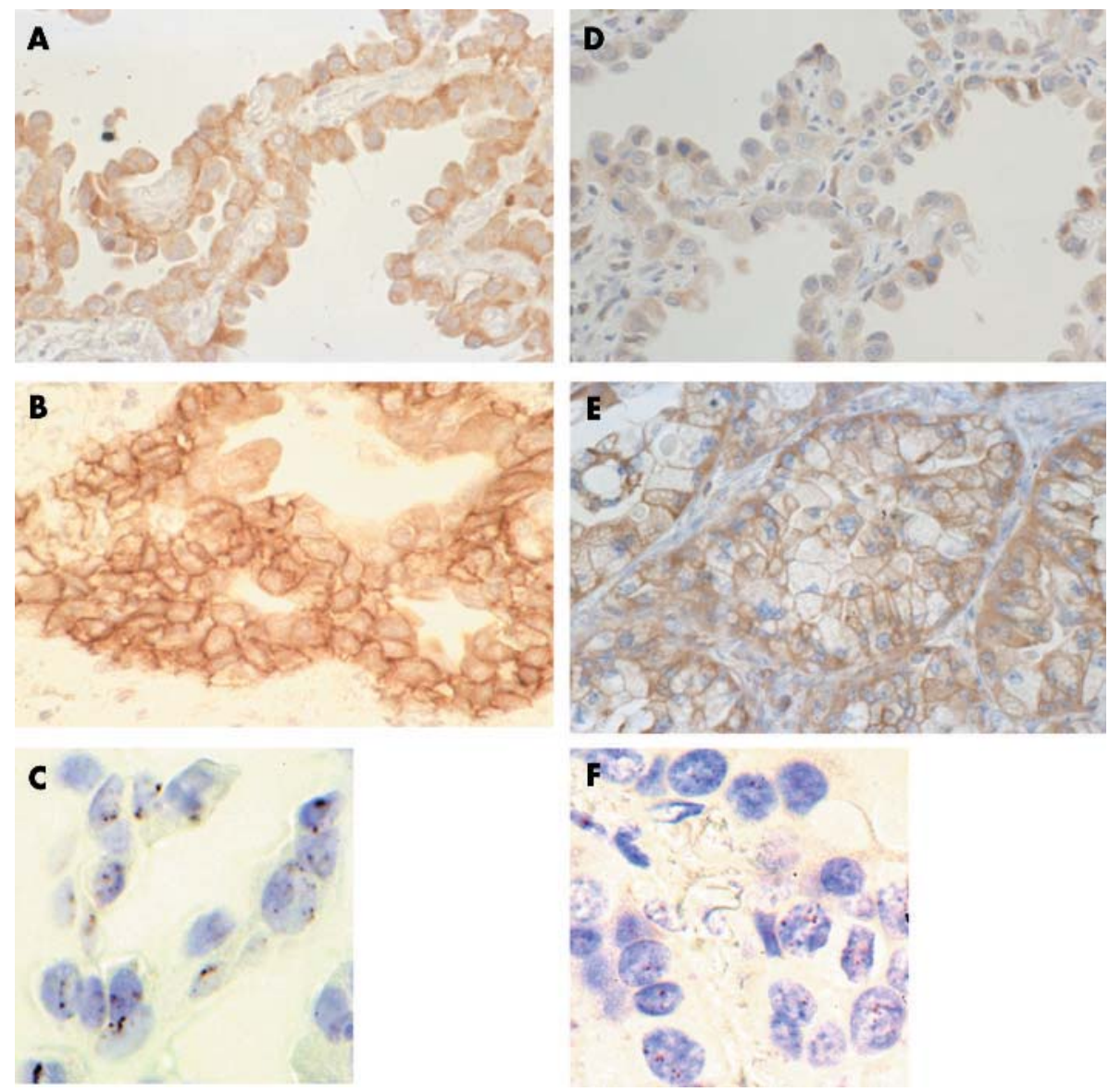

Figure 2 The results of protein expression and gene amplification of EGFR (epidermal growth factor receptor) and HER2 in adenocarcinoma. (A) Partial EGFR expression over part of the cell membrane in bronchioloalveolar carcinoma (BAC). (B) EGFR expression was seen over the entire cell membrane in the invasive component of adenocarcinoma with mixed subtypes (MX). (C) An EGFR gene cluster (more than six gene copies) seen in the case shown in (B). (D) Absence of HER2 expression in the membrane of a BAC lesion. (E) HER2 expression seen over the entire cell membrane in the invasive component of MX. (F) More than six gene copies of HER2 seen in the case shown in (E). 
Table 3 EGFR and HER2 protein expression in AAH and adenocarcinoma of the lung

\begin{tabular}{|c|c|c|c|c|c|c|}
\hline \multirow[b]{2}{*}{ Parameter } & \multicolumn{4}{|c|}{ Adenocarcinoma } & \multirow[b]{2}{*}{$\mathrm{p}$ Value } & \multirow[b]{2}{*}{ Total $(n=86$} \\
\hline & AAH $(n=14)$ & BAC $(n=31)$ & Early $M X(n=22)$ & Overt $M X(n=33)$ & & \\
\hline EGFR & 0 & $1(3.2 \%)$ & 8 (36.4\%) & $15(45.6 \%)$ & $<0.0001$ & 24 (27.9\%) \\
\hline HER2 & 0 & $1(3.2 \%)$ & $6(27.3 \%)$ & 11 (33.3\%) & 0.0034 & $18(20.9 \%)$ \\
\hline $\begin{array}{l}\text { Synchronous expression } \\
\text { pattern }\end{array}$ & - & $1(10 \%)$ & $3(30 \%)$ & $6(60 \%)$ & $<0.0001$ & 10 (11.6\%) \\
\hline
\end{tabular}

The Kruskal Wallis test was used to assess the $p$ values among BAC, early $M X$, and overt $M X$.

AAH, atypical adenomatous hyperplasia; BAC, bronchioloalveolar carcinoma; EGFR, epidermal growth factor receptor; MX, adenocarcinoma with mixed subtypes.

antibody (Zymed) and reported EGFR expression in $75 \%$ of adenocarcinomas using their own criteria. ${ }^{7}$ Various frequencies of EGFR expression have been reported previously because there is as yet no generally accepted standard method for the evaluation of EGFR expression in carcinoma of the lung. ${ }^{6-8}$ Moreover, evaluation by semi-quantitative methods may be difficult, because the staining intensity is affected by fixation conditions. ${ }^{22}$ Partial membranous expression, which was considered to be positive in the study of Hirsch et al, was seen in a few BAC samples in our study, but we only considered entire membranous expression to be positive.

\section{"Our results suggest that synchronous expression of EGFR and HER2 may also be associated with the development of adenocarcinoma of the lung"}

EGFR and HER2 protein overexpression without gene amplification were seen frequently. Similarly, discrepancies between HER2 gene amplification detected by FISH and protein expression have been reported in NSCLC. ${ }^{12}{ }^{23}$ Such discrepancies have also been detected using CISH in other carcinomas. ${ }^{14} 15$ These observations may be the result of the quality of fixation and tissue processing, or disturbances in transcriptional or post-transcriptional mechanisms. EGFR and HER 2 are growth factors, and enhanced transcription in the absence of gene amplification is a well recognised mechanism for cellular function through enhanced transcription of mRNA by phosphorylation of tyrosine kinase acting on growth factors and regulators of cell growth and proliferation. ${ }^{13}$

In conclusion, EGFR and HER2 gene amplification may be associated with the late stages of adenocarcinoma of the lung and the expression of the protein encoded by these genes may also be associated with the development of this disease. Protein expression was not associated with gene amplification, and other mechanisms should be considered in most cases. Further studies, including analyses of the mechanism involved in upregulation of these proteins, are necessary.

Table 4 Correlation between protein expression and gene amplification for EGFR and HER2 in adenocarcinoma of the lung

\begin{tabular}{llll}
\hline & & \multicolumn{2}{l}{ Gene amplification } \\
\cline { 3 - 4 } Parameter & Present & None \\
\hline Protein expression & Positive & 3 & 21 \\
EGFR & Negative & 1 & 61 \\
\multirow{2}{*}{ HER2 } & Positive & 2 & 16 \\
& Negative & 0 & 68 \\
\hline \multirow{2}{*}{ EGFR, epidermal growth factor receptor. }
\end{tabular}

Take home messages

- EGFR and HER2 gene amplification was seen only in the invasive components of adenocarcinoma with mixed subtypes $(M X)$ and therefore appears to be a late event in the development of adenocarcinoma of the lung

- EGFR and HER2 protein expression increased significantly as lesions progressed from atypical adenomatous hyperplasia to bronchioloalveolar carcinoma, early $M X$, and overt $M X$, and may be associated with the development of adenocarcinoma of the lung

- EGFR and HER2 protein expression was frequently seen without gene amplification, so that other mechanisms apart from gene amplification may be associated with protein expression

\section{Authors' affiliations}

H Awaya, Y Takeshima, O Furonaka, K Inai, Department of Pathology, Graduate School of Biomedical Sciences, Hiroshima University, 1-2-3 Kasumi, Minami-ku, Hiroshima 734-8551, Japan

N Kohno, Department of Molecular and Internal Medicine, Graduate School of Biomedical Sciences, Hiroshima University

\section{REFERENCES}

1 Travis WD, Colby TV, Corrin B, et al. World Health Organisation histological typing of lung and pleural tumors, 3rd ed. Berlin: Springer-Verlag, 1999.

2 Hayashi $\mathbf{H}$, Ito T, Yazawa T, et al. Reduced expression of p27/kipl is associated with the development of pulmonary adenocarcinoma. J Pathol 2000;192:26-31.

3 Seiki N, Takasu T, Mandai K, et al. Expression of eukaryotic initiation factor $4 \mathrm{E}$ in atypical adenomatous hyperplasia and adenocarcinoma of the human peripheral lung. Clin Cancer Res 2002;8:3046-53.

4 Awaya H, Takeshima Y, Yamasaki M, et al. Expression of MUC1, MUC2, MUC5AC, and MUC6 in atypical adenomatous hyperplasia, bronchioloalveolar carcinoma, adenocarcinoma with mixed subtypes, and mucinous bronchioloalveolar carcinoma of the lung. Am J Clin Pathol 2004;121:644-53.

5 Olayioye MA, Neve RM, Lane HA, et al. The ErbB signaling network: receptor heterodimerization in development and cancer. EMBO J 2000;19:3159-67.

6 Hirsh HR, Varella-Garcia M, Bunn Jr PA, et al. Epidermal growth factor receptor in non-small cell lung carcinomas: correlation between gene copy number and protein expression and impact on prognosis. J Clin Oncol 2003;21:3798-807.

7 Mukohara T, Kudoh S, Yamauchi S, et al. Expression of epidermal growth factor receptor (EGFR) and downstream-activated peptides in surgically excised non-small-cell lung cancer (NSCLC). Lung Cancer 2003;41:123-30.

8 Selvaggi G, Novello S, Torri V, et al. Epidermal growth factor receptor overexpression correlates with a poor prognosis in completely resected nonsmall-cell lung cancer. Ann Oncol 2004;15:28-32.

9 Sridhar SS, Seymour L, Shepherd FA. Inhibitors of epidermal-growth-factor receptors: a review of clinical research with a focus on non-small cell lung cancer. Lancet Oncol 2003;4:397-406.

10 Kristiansen G, Yu Y, Petersen S, et al. Overexpression of c-erbB2 protein correlates with disease-stage and chromosomal gain at the c-erbB2 locus in non-small cell lung cancer. Eur J Cancer 2001;37:1089-95.

11 Nakamura H, Saji H, Ogata A, et al. Correlation between encoded protein overexpression and copy number of the HER2 gene with survival in non-small cell lung cancer. Int J Cancer 2003;103:61-6. 
12 Heinmoller $\mathbf{P}$ Gross $\mathrm{C}$, Beyser $\mathrm{K}$, et al. HER2 status in non-small cell lung cancers: results from patient screening for enrolment to a phase II study of Herceptin. Clin Cancer Res 2003;9:5238-44.

13 Hirsch FR, Varella-Garcia M, Franklin WA, et al. Evaluation of HER2/neu gene amplification and protein expression in non-small cell lung carcinomas. Br J Cancer 2002;86:1449-56.

14 Tanner M, Gancberg D, Leo AD, et al. Chromogenic in situ hybridization. A practical alternative for fluorescence in situ hybridization to detect HER-2/neu oncogene amplification in archival breast cancer samples. Am J Pathol 2000;157:1467-72.

15 Zhao J, Wu R, Au A, et al. Determination of HER2 gene amplification by chromogenic in situ hybridization (CISH) in archival breast carcinoma. Mod Pathol 2002; 15:657-65.

16 Savinainen KJ, Saramaki OR, Linja MJ, et al. Expression and gene copy number analysis of ERBB2 oncogene in prostate cancer. Am J Pathol 2002;160:339-45.

17 Tanskanen M, Jahkola T, Asko-Seljavaara S, et al. HER2 oncogene amplification in extramammary Paget's disease. Histopathology 2003:42:575-9.

18 Dandachi N, Dietze O, Hauser-Kronberger C. Chromogenic in situ hybridization: a novel approach to a practical and sensitive method for the detection of HER2 oncogene in archival human breast carcinoma. Lab Invest 2002;82: 1007-14

19 Onn A, Correa AM, Gilcrease M, et al. Synchronous overexpression of epidermal growth factor receptor and HER2-neu protein is a predictor of poor outcome in patients with stage I non-small cell lung cancer. Clin Cancer Res 2004; 10:136-43

20 Saad RS, Liu Y. Han H, et al. Prognostic significance of HER2/neu, p53, and vascular endothelial growth factor expression in early stage conventional adenocarcinoma and bronchioloalveolar carcinoma of the lung. Mod Pathol 2004; 17:1235-42

21 Tubbs RR, Pettay PC, Roche MH, et al. Discrepancies in clinical laboratory testing of eligibility for trastuzumab therapy: apparent immunohistochemical false-positives do not get the message. J Clin Pathol $2001 ; 19: 2714-21$.

22 Atkins D, Reiffen KA, Tegtmeier CL, et al. Immunohistochemical detection of EGFR in paraffin-embedded tumor tissues: variation in staining intensity due to choice of fixative and storage time of tissue sections. J Histochem Cytochem 2004;52:893-901.

23 Cox G, Vyberg M, Melgaard B, et al. Herceptest: HER2 expression and gene amplification in non-small cell lung cancer. Int J Cancer 2001;92:480-3.

\section{bmjupdates+}

bmjupdates+ is a unique and free alerting service, designed to keep you up to date with the medical literature that is truly important to your practice.

bmjupdates+ will alert you to important new research and will provide you with the best new evidence concerning important advances in health care, tailored to your medical interests and time demands.

Where does the information come from?

bmjupdates+ applies an expert critical appraisal filter to over 100 top medical journals A panel of over 2000 physicians find the few 'must read' studies for each area of clinical interest

Sign up to receive your tailored email alerts, searching access and more...

www.bmjupdates.com 